\title{
Angioplasty and restenosis
}

\author{
Endothelium remains the sticking point
}

Over 5000 angioplasties were performed for coronary artery disease in the United Kingdom during 1988. The corresponding figure for the United States was 100000 , where the frequency of this procedure now rivals that of coronary artery bypass grafting. ${ }^{1}$ The appeal of correcting an arterial obstruction through a percutaneous catheter is obvious, but the technique is marred by the possibility of restenosis. The frequency of this complication depends in part on the vigour with which it is sought, but it affects at least one third of cases. $^{2}$

Our better understanding of the function of the endothelium provides possible explanations for why restenosis may follow an initially successful angioplasty. As well as having hormonal and metabolic functions, ${ }^{3+}$ this thin monolayer of cells exerts a fine vasomotor control over the entire cardiovascular system. The complexity of this tissue is matched by its delicacy-indeed, minimal trauma easily removes it. Although the endothelium can regrow quite quickly, some of its functions may take several months to recover. ${ }^{5}$ Endothelium usually maintains a non-thrombogenic surface by producing prostacyclin, tissue plasminogen activator, antithrombotic cell surface proteins, heparin, and endothelium derived relaxing factor. If injured the endothelium may become procoagulant, promoting platelet adhesion and activating the coagulation cascade. ${ }^{4}$ Removal of or damage to the endothelium at angioplasty thus predisposes the vessel to thrombosis and spasm. ${ }^{6}$ Use of aspirin, heparin, nitrovasodilators, and calcium channel blockers may hold this in check, but this approach has no effect on the later chances of developing restenosis.

Angioplasty entails more than removing the intimal endothelium. The successful relief of atheromatous obstruction is brought about by fracture of the plaque together with substantial injury to the vessel wall. The endothelial denudation at the site of angioplasty is accompanied by longitudinal tears in the intima, tangential splitting of the media, and a degree of stretching of tissue adjacent to the areas of atheroma. ${ }^{27}$ Intramural thrombus often develops within the cracks in the vessel wall, which may later become the focus for microvascular proliferation. ${ }^{8}$ Healing is characterised by the remodelling of the intimal and medial damage, a process that includes the microvessel endothelium of the vasa vasorum and regrowth of the intimal endothelium.

The process of repair after angioplasty continues over several months, involving re-endothelialisation, proliferation of vascular smooth muscle cells, and remodelling of the extracellular matrix proteins ${ }^{8}$ Excessive growth of smooth muscle cells and accumulation of the matrix proteins (a process linked to accelerated atherosclerosis) cause restenosis and the recurrence of symptoms. The differentiation of smooth muscle cells is regulated by the action of mitogens (such as platelet derived growth factor and insulin-like growth factor 1) and the opposing actions of inhibitors (such as transforming growth factor $\beta$ ) ${ }^{8}$ Normal endothelium secretes heparin proteoaminoglycan, which not only blocks platelet aggregation but potentiates the activity of transforming growth factor $\beta$, thus inhibiting the growth of smooth muscle. ${ }^{9}$

After endothelial removal by experimental angioplasty platelets adherent to exposed subendothelial tissues release both mitogens and factors that neutralise endothelium derived heparin, ${ }^{810}$ thereby promoting hyperplasia of smooth muscle cells. Subsequently the endothelium regrows, smooth muscle cells differentiate, and matrix proteins remodel, with peak intimal hyperplasia occurring between four and 12 weeks, ${ }^{11}$ which reflect the clinical course of those patients whose arteries restenose. A local imbalance between growth promoters and inhibitors at the site of angioplasty is the likely explanation of the excessive proliferation of smooth muscle that leads to restenosis.

Drug treatment to prevent restenosis has so far not succeeded. Most of the compounds that have been used affect either coagulation or vessel tone rather than mimicking endothelial control of cell division. Although experimental thrombocytopenia substantially inhibits intimal hyperplasia after experimental angioplasty in animals, ${ }^{12}$ neither aspirin nor dipyridamole affects restenosis, ${ }^{13}$ possibly because the cyclo-oxygenase pathway is not involved. ${ }^{2}$ Moreover, recent trials have found that neither prostacyclin ${ }^{2}$ nor a thromboxane antagonist $^{14}$ affected the incidence of restenosis after angioplasty, presumably for the same reason. More potent inhibitors of platelet function have profound effects on haemostasis, making their long term use impractical. Trials of calcium antagonists, fish oil supplements, and warfarin have shown no benefit. Heparin used short term has no effect on restenosis. The theoretical appeal of long term treatment with heparin to substitute for endothelial regulation of smooth muscle cell growth has, however, become clear. Clinical trials of subcutaneous heparin given for three or four months after angioplasty, with doses adjusted to minimise the risk of osteoporosis, are currently under way both in the United Kingdom and in North America. Results from these trials should be available early next year. Clinical trials of inhibitors 
of angiotensin converting enzyme are also under way; animal studies have shown that they limit the proliferative response to vascular injury. ${ }^{15}$ Future treatments might include specific monoclonal antibodies, which can block receptors for platelet adhesion or mitogens such as platelet derived growth factor.

Restenosis is the greatest challenge facing angioplasty. New treatments and an explanation of individual differences in susceptibility to restenosis will depend on a better understanding of vascular repair and the proliferation of smooth muscle cells.

ADRIAN J B BRADY

Medical Research Council Clinical Training Fellow

Department of Cardiac Medicine

JOHN B WARREN

British Heart Foundation Senior Lecturer

Department of Applied Pharmacology,

National Heart and Lung Institute,

London SW3 6LY

1 Hubner PJB. Cardiac interventional procedures in the UK during 1988. Br Heart $f$ 1990;64:36-7. 2 Gershlick AH, de Bono DP. Restenosis after angioplasty. Br Heart $\mathcal{f}$ 1990;64:251-3.
3 Henderson AH. Endothelium in control. Br Heart $f$ 1991;65:116-25.

4 Warren J B, ed. The endothelium - an introduction to current research. New York: Wiley-Liss, 1990

Shimokawa H, Aarhus LL, Vanhoutte PM. Porcine coronary arteries with regenerated endothelium have a reduced endothelium-dependent responsiveness to aggregating platelets and serotonin. Circ Res 1987;61:256-70.

6 Maseri $\mathrm{A}$, ed. Platelet adhesion and aggregation mechanisms: importance in acute cardiovascula syndromes and effects of thromboxane A2 antagonism. Circulation 1990;81 (suppl I):1-82.

Waller BF. Crackers, stretchers, drillers, scrapers, shavers, burners, welders, melters - the future treatment of coronary artery disease? A clinical-morphologic assessment. I Am Coll Cardiol 1989;13:969-87.

8 Forrester JS, Fishbein M, Helfant R, Fagin J. A paradigm for restenosis based on cell biology: clues for the development of new preventive strategies. F Am Coll Cardiol 1991;17:758-69.

9 McCaffrey TA, Falcone DJ, Brayton CF, Agarwal LA, Welt FGP, Weksler BB. Transforming $C$ growth factor $-\beta$ activity is potentiated by heparin via dissociation of the transforming growth factor- $\beta / \alpha 2$-macroglobulin inactive complex. $\mathcal{F}$ Cell Biol 1989;109:441-8.

10 Harker LA, Ross R, Glomset JA. The role of endothelial cell injury and platelet response in atherogenesis. Thromb Haemostat 1978;39:312-21.

11 Clowes AW, Reidy MA, Clowes MM. Mechanisms of stenosis after arterial injury. Lab Invest 1983;49:208-15.

12 Friedman RJ, Stemerman MB, Wenz B, Moore S, Gauldie J, Gent M, et al. The effect of $\frac{\bar{\sigma}}{D}$ thrombocytopenia on experimental arteriosclerotic lesion formation in rabbits. $\mathcal{F}$ Clin Invest $\mathbb{D}$

13 Schwartz LS, Bourassa MG, Lesperance J, Aldridge HE, Kazim F, Salvatori VA, et al. Aspirin and dipyridamole in the prevention of restenosis after percutaneous transluminal coronary dipyridamole in the prevention of restenosis after percutaneous transluminal coronary $\overrightarrow{0}$

14 Serruys PW, Rutsch W, Heyndrickx G, Danchin N, Mast EG, Wijs W, et al. Thromboxane A2 receptor blockade does not prevent restenosis, despite near complete platelet inhibition. A $\vec{\omega}$

multicentre randomised clinical trial. Circulation (in press).
15 Powell JS, Clozel JP, Muller RKM, Kuhn H, Hefti F, Hosang M, Baumgartner HR. Inhibitors of $\frac{\partial}{\partial}$ angiotensin-converting enzyme prevent myointimal proliferation after vascular injury. Science $1989 ; 245: 186-8$.

\section{Hypertension and non-insulin dependent diabetes}

\section{Chicken, egg, tablets, or insulin resistance?}

The association between non-insulin dependent diabetes mellitus and hypertension is independent of age and obesity. ${ }^{12}$ When the two diseases coexist hypertension antedates the diagnosis of diabetes some eight times more commonly than the reverse sequence. ${ }^{3}$ One possible reason is the diabetogenic effect of drugs used to treat hypertension.

Two Swedish groups have reported a markedly increased incidence of non-insulin dependent diabetes mellitus in treated hypertensive patients. ${ }^{+7}$ Bengtsson et al studied nearly 1500 women over 12 years and found that those treated with a thiazide had an almost fivefold increased risk of diabetes, while those using $\beta$ blockers showed a sixfold increase. ${ }^{4}$ All of the 16 hypertensive women who developed diabetes were taking antihypertensive drugs, whereas no untreated hypertensive woman developed diabetes. ${ }^{5}$ Skarfors and colleagues have previously reported a $3 \cdot 6$-fold increased risk of diabetes in hypertensive middle aged men in Uppsala. ${ }^{6}$ In this issue they report the full analysis of the 10 year follow up of this study, which showed that antihypertensive treatment is associated with a nearly twofold increase in the risk of diabetes when, among other things, body mass index and systolic blood pressure at the beginning of the study are controlled for (p 755).?

There are, however, problems with this interpretation. Another longitudinal study, from Finland, recently suggested that glucose intolerance antedates rather than results from hypertension. ${ }^{8}$ This study examined glucose tolerance and blood pressure in middle aged men three times over 18 years. The blood glucose concentration one hour after a glucose load was higher in those who went on to develop hypertension than in those who remained normotensive, and this association was independent of age, obesity, alcohol intake, and blood pressure at the initial assessment. Men in the top one third of the one hour blood glucose distribution in 1968 had a $1 \cdot 7$-fold increased risk of hypertension 18 years later. As none of these men was taking antihypertensive drugs at the baseline examination these observations suggest that the association between glucose intolerance and hypertension may not be one of cause or effect but the result of a common antecedent.
Insulin resistance is a necessary, but not sufficient, condition for the development of non-insulin dependent diabetes $\stackrel{\mathbb{Q}}{\stackrel{9}{-}}$ mellitus. ${ }^{9-13}$ Several studies over the past five years have also $\vec{\oplus}$ documented insulin resistance in untreated patients with $\stackrel{\bullet}{-}$ essential hypertension, ${ }^{14}$ is although the importance of insulin 0 resistance in the aetiology of hypertension may differ substantially between ethnic groups. ${ }^{16}$ Hypertensive people show a specific resistance to insulin stimulated non-oxidative glucose disposal but not to the other metabolic effects of $\propto$ insulin. ${ }^{14}$

In people with good $\beta$ cell reserve insulin resistance produces a compensatory increase in insulin production to maintain fasting normoglycaemia. ${ }^{9}$ Hypertension may therefore result from hyperinsulinaemia rather than from insulin resistance. ${ }^{17-28}$ This could be mediated by insulin induced renal retention of sodium ${ }^{29}$ or the effect of insulin on the $\frac{5}{3}$ sympathetic nervous system,$^{30}$ or on the handling of sodium by the arterial smooth muscle cell membrane. ${ }^{312}$ When the responsiveness of $\beta$ cells to glucose is no longer sufficient to sustain fasting normoglycaemia diabetes will supervene ${ }^{9-11}-$ insulin resistance is then no longer paralleled by hyper- $N$ insulinaemia. The hope that the separate roles of insulin $\frac{D}{0}$ resistance and hyperinsulinaemia in controlling blood pressure might be disentangled in patients with non-insulin dependent diabetes mellitus, however, is confounded by the ${ }^{\omega}$ preliminary findings that proinsulin-like molecules may be a contributory factor in this group. ${ }^{3}$

Only longitudinal studies can determine whether insulin $\stackrel{\mathbb{\Phi}}{\rightarrow}$ resistance can explain the coincidence of hypertension and 7 non-insulin dependent diabetes mellitus and the contribution of antihypertensive drugs. Salomaa et al suggested that the $\stackrel{\mathbb{Q}}{\mathcal{Q}}$ raised blood glucose concentration one hour after a glucose $\stackrel{\mathbb{Q}}{\varnothing}$ load is an indication of insulin resistance and that insulin resistance may antedate, and even initiate, hypertension. ${ }^{8}$ In 8 that study the contribution of glucose intolerance to blood? pressure was weak $-6 \%$ of the variance of systolic pressureco and $3 \%$ of that of diastolic pressure by regression analysis. $\stackrel{?}{?}$ This, however, may be a conservative estimate, both because of the poor reproducibility of the test and because blood 